\title{
Synergistic effect of doping with nitrogen and molybdenum on the photocatalytic properties of thin titania films
}

\section{Ratova ${ }^{1 *}$, G.T. West ${ }^{1}$, P.J. Kelly ${ }^{1}$ X Xia ${ }^{2 *}$, Y. Gao ${ }^{2}$}

${ }^{1}$ Surface Engineering Group, School of Engineering, Manchester Metropolitan University, Manchester, M1 5GD, phone +44(0) 161247 4643; fax +44(0) 161247 4693;

${ }^{2}$ Hubei Collaborative Innovation Center for Advanced Organic Chemical Materials, Ministry-of-Education Key Laboratory for the Green Preparation and Application of Functional Materials, Faculty of Materials Science and Engineering, Hubei University, Wuhan City, Hubei Province, P.R. China, 430062

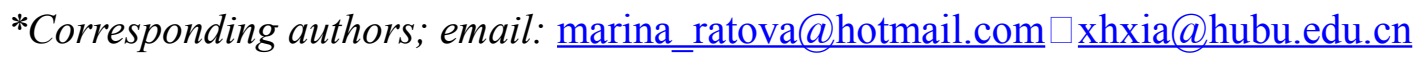

\begin{abstract}
Doping of titania with metal and non-metal elements provides a simple and efficient pathway to significant enhancement of photocatalytic properties. In this work titania thin films codoped with molybdenum and nitrogen were prepared by reactive magnetron sputtering. Additionally, coatings doped only with nitrogen were prepared under identical deposition conditions for comparison purposes. Coatings were annealed at $873 \mathrm{~K}$ in air and analysed by Raman spectroscopy, XRD and XPS. Photocatalytic properties of the coatings were evaluated on the basis of the photodegradation rate of methylene blue dye under UV, fluorescent and visible light. It was found that the photocatalytic activity of co-doped samples was significantly higher than that of $\mathrm{N}$-doped coatings. Unlike $\mathrm{N}$-doped titania films, co-doped coatings exhibited high photocatalytic activity under the fluorescent light source and noticeable activity under visible light. The possible mechanism for the enhancement of the photocatalytic activity of Mo-N co-doped titania coatings is discussed.
\end{abstract}

\section{Introduction}

Titanium dioxide (or titania) is widely used as a photocatalyst, with its photocatalytic properties being discovered more than 60 years ago [1]. It finds applications in various areas, such as building materials, antibacterial coatings, self-cleaning surfaces, etc. However, the application of titanium dioxide is restricted due to its high band gap value $(3.2 \mathrm{eV}$ for 
anatase), which means that UV irradiation is required for its excitation. As UV constitutes just $1-2 \%$ of the solar spectrum, for many practical applications it is necessary to shift the photocatalytic activity of titanium dioxide into the visible range. Several methods of achieving this are described in the literature, with doping of titanium dioxide with either metallic or non-metallic elements as one of the most promising and well-studied.

Doping titanium dioxide with non-metal atoms, such as carbon, nitrogen, phosphorus, etc. narrows the band gap due to a mixing of the dopant p-states with the p-states of oxygen forming the valence band of titanium dioxide [2]. Of the range of possible non-metal dopants, nitrogen is one of the most described in literature to improve the photocatalytic activity of titanium dioxide [3-5] and extend activity into the visible range. The nitrogen atom has a size comparable with the size of an oxygen atom, thus it can be easily introduced into the titania structure in either substitutional or interstitial positions [6].

Doping with transition metal ions is reported to create impurity levels near the conduction band, that may perform as trapping centres, which extend the lifetime of photogenerated electrons and holes [7]. At present, there is no uniform theory explaining the choice of the doping element to maximise the photocatalytic properties in the visible range. However, there are some reports, which enable a reasoned choice for the doping elements. It is reported that the best results for transition metal doping can be achieved when the ionic radius of the doping metal is close to that of titanium [8], to enable incorporation into the titania lattice. Of the variety of candidate metals described in literature, transition metals such as tungsten [9], chromium [10], vanadium [11] and molybdenum [12] are mentioned as efficient dopants for shifting the activity to the visible range.

However, both metal and non-metal doping have limits to their application due to some restricting factors. Excessive metal doping may lead to the formation of recombination sites 
for photogenerated electrons and holes, thus reducing the photocatalytic activity. Excessive nitrogen doping leads to the formation of extra nucleation sites, that may lead to anatase-torutile transformation at lower temperatures [13], which results in a significant decrease of photocatalytic activity.

The idea of simultaneously co-doping titania with metallic and non-metallic elements has been rapidly explored by many researches in the past few years. Nitrogen is typically used as the non-metallic element, while the metals chosen may vary. Several works have recently been published on the co-doping of titanium dioxide with both molybdenum and nitrogen, using a variety of methods to produce the coatings, such as sol-gel [7], hydrolysisprecipitation [14], etc. However, in this work, titanium dioxide coatings co-doped with molybdenum and nitrogen were deposited by reactive magnetron sputtering. Co-sputtering from a host target and a dopant target in the presence of a reactive gas is proven to be a convenient and scalable technique, which provides straightforward control over the dopant levels in the host material. The doped coatings were compared to pure titania coatings, as well as coatings singly-doped with nitrogen and molybdenum only.

\section{Experimental}

\subsection{Coatings deposition}

The coatings were deposited by reactive magnetron sputtering in a Teer Coatings Ltd. UDP 450 system (Figure 1 ). Three $300 \mathrm{~mm} \times 100 \mathrm{~mm}$ type II unbalanced planar magnetrons were installed vertically opposed through the chamber walls; two magnetrons were fitted with titanium targets $(99.5 \%$ purity) and one with a $99.95 \%$ pure molybdenum target. The magnetrons with the titanium targets were in the closed field configuration and driven in midfrequency $(100-350 \mathrm{kHz})$ pulsed DC mode using a dual channel Advanced Energy Pinnacle

Plus supply at a frequency of $100 \mathrm{kHz}$ and a duty of $50 \%$ (in synchronous mode) at a constant 
time-averaged power of $1 \mathrm{~kW}$ each. In order to achieve the desired doping level, the magnetron with the molybdenum target was driven at $100 \mathrm{~W}$ in continuous DC mode using an Advanced Energy MDX power supply. Previous work by the authors has shown that the best results obtained for molybdenum-doped coatings were for those containing 2.4 at. $\%$ of molybdenum [13]. The reactive sputtering process was carried out in an argon:oxygen atmosphere at $0.3 \mathrm{~Pa}$, and was controlled by optical emissions monitoring using an operating set point $\left(15 \%\right.$ of the full metal signal) previously found to produce stoichiometric $\mathrm{TiO}_{2}$ coatings [15]. The glass substrates were ultrasonically pre-cleaned in propanol and placed onto the substrate holder, which was rotated continuously during the deposition process at 4 rpm at a distance of $100 \mathrm{~mm}$ from the magnetrons. The nitrogen flow was controlled using a mass flow controller in the range from 0 to $10 \mathrm{sccm}$ to vary dopant levels. Two arrays of coatings were deposited during this work: titania doped with nitrogen at different levels (sample IDs N1-N10), and titania with a fixed molybdenum content and varying nitrogen levels (sample IDs MoN1-MoN10). Undoped titania coatings were additionally deposited for the purpose of photocatalytic and structural property comparisons. Coatings singly doped with molybdenum (deposited under identical conditions) were described earlier elsewhere [13].

\subsection{Coatings characterization}

The crystallinity of the annealed coatings was analysed by grazing incidence X-ray diffraction (GIXRD) (Panalytical Xpert, angle of incidence $=3^{\circ}$ ) and Raman spectroscopy (Renishaw Invia, $514 \mathrm{~nm}$ laser). XPS analysis was also carried out using a VG Multilab 2000 system employing an $\mathrm{AlK} \alpha$ source with the pass energy of $25 \mathrm{eV}$. Transmittance of the coatings used for calculation of the band gaps was measured with Ocean Optics USB 2000+ UV-visible spectrometer. 


\subsection{Evaluation of photocatalytic activity}

The determination of photocatalytic activity was carried out using the methylene blue (MB) degradation test. $\mathrm{MB}$ is an organic dye with molecular formula $\mathrm{C}_{16} \mathrm{H}_{18} \mathrm{ClN}_{3} \mathrm{~S}$, and is often used as an indicating organic compound to measure the activity of photocatalysts. An aqueous solution of $\mathrm{MB}$ shows strong optical absorption at approximately $665 \mathrm{~nm}$ wavelength. Changes in the absorption peak height are used for monitoring the concentration of $\mathrm{MB}$, and hence its degradation in contact with a photocatalytic surface.

Prior to the photocatalytic measurements, coating samples of equal size $\left(1.5 \times 2.5 \mathrm{~cm}^{2}\right)$ were immersed for $30 \mathrm{~min}$ in a conditioning solution of methylene blue in the dark for preabsorption of $\mathrm{MB}$ on the test surfaces to exclude the effect of absorption during the photocatalytic experiment. The photocatalytic measurements were carried out for 1 hour in continuous mode. Samples were immersed into $40 \mathrm{ml}$ of $\mathrm{MB}$ aqueous solution; the concentration of methylene blue solution used in the work was $1.5 \mu \mathrm{mol} / 1$ - this concentration was defined experimentally to be able to detect photocatalytic response of each tested coatings in 1 hour experiment. The absorption peak height of methylene blue solution was measured with an Ocean Optics USB 2000+ spectrometer with continuous magnetic stirring. Each coating was tested both under UV and fluorescent light sources; $2 \times 15 \mathrm{~W} 352$ nm Sankyo Denki BLB lamps were used as the UV light source and $2 \times 15 \mathrm{~W}$ Ushio fluorescent lamps as the fluorescent light source. Selected coatings were additionally tested under a visible light source. The visible light source was simulated by combining a fluorescent light source with a Knight Optical $395 \mathrm{~nm}$ long pass UV filter. The natural decay rate of methylene blue (without the photocatalyst present) under each type of light source was measured for reference purpose, as well as the degradation rate of methylene blue in contact with photocatalytic surface but without light irradiation (i.e. in the dark). In both cases the decay rate of methylene blue was of zero order and, thus was neglected in the following 
calculations, meaning any changes in the absorption peak height could be attributed to the photocatalytic activity [12].

According to the Lambert-Beer law, the concentration of the dye is proportional to the absorbance value:

$$
\mathrm{A}=\varepsilon \mathrm{cl}
$$

where: A is absorbance, $\varepsilon$ is the molar absorbance coefficient; / is the optical length of the cell in which the photocatalyst is immersed into the MB. A heterogeneous catalysis process can be described with the simplified form of the Langmuir-Hinshelwood equation [16]:

$$
\ln C O C=\text { kat } \quad \ln C O C=\text { kat }
$$

where $C_{0}$ and $C$ are the concentrations of $\mathrm{MB}$ solution at time 0 and time $t$ of the experiment, respectively. A plot of $C_{d} / C$ versus time is linear, where the gradient gives a value of the first order rate constant, $k_{a}$. The concentration of methylene blue was found using the following equation [17]:

$$
\mathrm{CCO}=\mathrm{AtAt}=\mathrm{O}
$$

where $A_{t=o}$ and $A_{t}$ is the absorption of methylene blue at $665 \mathrm{~nm}$ at time 0 , and the time of the experiment, respectively. Thus, substituting $\left(\mathrm{A}_{\mathrm{t}=0} / \mathrm{A}_{\mathrm{t}}\right)$ into Equation 2 yields a linear relationship, where the gradient gives a value of the first order rate constant, $\mathrm{k}_{\mathrm{a}}$.

\section{Results}

\subsection{Coatings overview}

The overview of the coatings produced, including their thicknesses (measured by stylus profilometry) and compositional properties, measured by EDX and verified with XPS, is presented in Table 1. Information on molybdenum-doped titania coatings deposited earlier 
under identical conditions (2.4 at.\% of Mo) studied in one of our earlier works [18] is given for reference purposes. The content of molybdenum in the co-doped coatings is not included in this table, as this parameter was not varied. The coatings produced in the present work contained $2.8-2.9$ at. $\%$ of Mo.

Despite using the same range of flow rates, it can be seen that the nitrogen content was significantly lower in the N-doped coatings, compared to co-doped coatings. Due to the low values of nitrogen content in coatings $\mathrm{N} 1-\mathrm{N} 5$ it could not be quantified with the techniques used here.

According to the results of XRD and Raman spectroscopy, all the as-deposited coatings were amorphous. In order to develop the crystal structure the samples of each coating were annealed in air at $873 \mathrm{~K}$ for $30 \mathrm{~min}$. After annealing the coatings were cooled gradually (4-5 hours) to avoid introducing stresses to the structure, and then re-analysed by Raman spectroscopy and XRD.

\subsection{Raman spectroscopy results}

The Raman spectra of the annealed N-doped and Mo-N co-doped titania coatings are presented in Figures 2 and 3, respectively. The Raman spectra of the N-doped coatings

(Figure 2) showed that all the coatings were in the anatase phase with typical anatase Raman bands observed at 144, 397, 516 and $638 \mathrm{~cm}^{-1}$.

The results of Raman spectroscopy of the Mo-N co-doped coatings showed a similar trend to the N-doped coatings (Figure 3). Thus, after annealing at $873 \mathrm{~K}$ all the coatings were crystalline with anatase peaks identical to those described above. A broad, weak peak observed at $971 \mathrm{~cm}^{-1}$ can be attributed to $\mathrm{Mo}=\mathrm{O}$ bond stretching [19].

\subsection{XRD results}


In a similar manner to the Raman spectroscopy results, the XRD results showed the presence of anatase peaks for all the coatings annealed at $873 \mathrm{~K}$, as shown in Figures 4 and 5 (JCPDS: 21-1272).

It can be seen that the $\mathrm{N}$-doped coatings retained the strong anatase $\left(\begin{array}{lll}1 & 0 & 1\end{array}\right)$ peak at $25.3^{\circ}$ through the entire set of coatings (Figure 4), while the Mo-N co-doped coatings showed a shift in texture towards the anatase $\left(\begin{array}{lll}0 & 0 & 4\end{array}\right)$ peak (at $37.8^{\circ}$ ) for the coatings with higher nitrogen content (starting from MoN5) (Figure 5) and anatase (l $\left.\begin{array}{lll}0 & 1\end{array}\right)$ for coatings MoN1 and MoN3.

No additional phases could be detected in the XRD patterns of the N-doped titania coatings, while for the Mo-N co-doped coatings several small peaks attributed to rutile and brookite titania can be seen. Additionally, coatings MoN7 and MoN10 exhibited the presence of a peak that can be attributed to molybdenum oxide; $\mathrm{MoO}_{3}$ (JCPDS: 35-0609).

\subsection{XPS results}

XPS analysis was conducted on selected coatings for the determination of the chemical states of molybdenum and nitrogen. Coatings MoN3, N3, MoN7 and N7 were selected as examples of doped / co-doped coatings deposited with low and high nitrogen flows, respectively. Figure 6 shows curve fitting for the Mo3d spectra of coatings MoN3 and MoN7, respectively. As a result of the peak fitting, two peaks at the binding energies of 231.8 and $234.9 \mathrm{eV}$ can be observed for both of the samples, which can be assigned to Mo3d5/2 and Mo3d $3 / 2$ photoelectrons, respectively.

The results of fitting for the XPS peak observed at a binding energy of $399 \mathrm{eV}$ for coatings MoN3 and MoN7 (Figure 7) assign it to the N1s peak at $398.0 \mathrm{eV}$ and the Mo3p3/2 peak at $399.5 \mathrm{eV}$. 
Therefore it can be concluded that in the co-doped samples, molybdenum co-exists in the form of $\mathrm{Mo}^{6+}$, as well as Mo-N-Ti (judging from its 3d and 3p binding energies). The N1s peak at a binding energy of $399 \mathrm{eV}$ is usually assigned to substitutional nitrogen incorporated into the titanium dioxide lattice via O-Ti-N linkage [20].

Comparing the XPS patterns of the co-doped coatings with the patterns of the nitrogen-doped coatings (Figures 7 and 8, respectively), it can be concluded that co-doping resulted in changes of the chemical state of the N species. The peaks seen in the XPS spectra of samples N3 and N7 can be deconvoluted into three peaks at binding energies of 397.5, 399.1 and $402.8 \mathrm{eV}$ (403.5 eV for N7). As in the case of the co-doped samples, the peak at $399 \mathrm{eV}$ can be interpreted as N1s substitutional nitrogen; while the other two peaks can be assigned to Ti$\mathrm{N}$ and Ti-O-N (interstitial nitrogen), respectively.

\subsection{Band gap calculation}

Optical band gap values of the coatings were calculated using the Tauc plot method [21] by plotting $(\alpha h v)^{1 / 2}$ versus $h v$ and extrapolating the linear region to the abscissa (where $\alpha$ is the absorbance coefficient, $h$ is Plank constant, $v$ is the frequency of vibration).

Examples of the band gap calculation for the N-doped and Mo-N co-doped coatings are presented in Figure 9. The calculated values of the optical band gaps are given in Table 2.

It can be seen that neither $\mathrm{N}$-doping, nor co-doping with $\mathrm{N}$ and Mo has a significant effect on the value of the band gap. The lowest band gap value obtained through the entire experimental array was $3.04 \mathrm{eV}$ (for sample MoN7), which corresponds to light with a wavelength of $408 \mathrm{~nm}$. Generally, the co-doped coatings exhibited a higher band gap shift towards the visible range than the $\mathrm{N}$-doped coatings. 
Some examples of MB $665 \mathrm{~nm}$ absorbance peak decay plots are given in Figure 10. The values of first order rate constant of the MB decomposition under UV, fluorescent and visible light are given in Table 2. Values of photocatalytic activity of undoped titania and Mo-doped titania are given for reference purposes.

For the N-doped only coatings, samples N1 and N3 show some increase in UV activity, compared to the undoped titania coating, but apart from these two results, the effect of Ndoping alone is not significant. However, the results for the co-doped coatings show a progressive increase in UV and fluorescent activity up to sample MoN10, with coatings MoN5 and MoN7 demonstrating the highest activity under both light sources. Visible light testing showed that these coatings also exhibited some activity under the visible light source, while for undoped / N-doped titania coatings this value was equal to zero.

\section{Discussion}

Incorporation of nitrogen atoms into the titania lattice is reported to extend the spectral response into the visible range. [5, 22]. Co-doping with metals and non-metals is described as having a synergistic effect on the photocatalytic activity of titania, as in addition to the extended spectral response of the photocatalyst, the metal facilitates the transfer of excited electrons and suppresses charge carrier recombination. In this case, enhanced photodecomposition can be attributed to the increased number of photogenerated $\cdot \mathrm{OH}$ radicals [23].

The results of photocatalytic tests showed that doping with nitrogen has a moderately positive effect on photocatalytic activity, while co-doping with nitrogen and molybdenum resulted in significant improvements in photocatalytic activity. The efficiency of $\mathrm{N}$-doped coatings under 
UV light, compared to that of undoped titania, was higher by a factor of 2 . However, despite widely published information about $\mathrm{N}$-doping as an efficient method of improving the photocatalytic properties under fluorescent / visible light, N-doped titania coatings studied in this work had a low efficiency of MB degradation under the fluorescent light source. As no noticeable band gap shift towards the visible range was observed, the increased photocatalytic activity under the fluorescent light source could only be attributed to improved electron-hole separation and the extended lifetime of charge carriers, as a result of nitrogen incorporation.

The results of the XPS showed that the presence of molybdenum has a significant influence on the content of nitrogen in the coatings and its position. As shown by Liu et. al, co-doping with $\mathrm{N}$ and Mo increases the solubility limits of both $\mathrm{N}$ and $\mathrm{Mo}$ in $\mathrm{TiO}_{2}$ [7]. This effect is described as being more pronounced in the case of nitrogen, as the solubility of $\mathrm{N}$ in titania is usually very low. The data obtained on the content of dopants in this work are in good agreement with this theory - the co-doped coatings have much higher nitrogen contents compared to N-doped titania. The content of molybdenum is also slightly higher than for Modoped titania prepared and annealed under identical conditions [18] (2.9 and 2.4 at. \%, respectively). Based on the XPS results, it can be assumed that the substitutional position of the nitrogen in the titania lattice has a positive effect on the photocatalytic activity. Thus, the activity of co-doped coatings was much higher compared to $\mathrm{N}$-doped coatings, where $\mathrm{N}$ coexisted in several forms. The photocatalytic activity of Mo-doped titania also was much lower than that seen for the co-doped coatings.

Summarising all the above, increased activity of co-doped coatings can be assumed to be a result of more efficient electron-hole separation, compared to undoped or singly Mo- or N- 
doped titania coatings, due to the synergistic effect of Mo-N co-doping. A mechanism of explaining more efficient charge carrier separation was proposed by Cheng et. al, who observed similar results for Mo-N co-doped coatings prepared by a hydrolysis-precipitation method [14]. The proposed mechanism is schematically shown in Figure 10. Nitrogen and molybdenum create local energy levels within the titania band gap, and therefore several ways of charge carrier excitation are available, and consequently more photoinduced charge carriers can be efficiently separated to participate in the photocatalytic process. Co-doped coatings with optimum content of nitrogen and molybdenum demonstrate significantly higher photocatalytic activity, due to more efficient charge carrier separation and their extended lifetimes. A shift of the band gap towards the visible range, compared to undoped titania, enables the presence of photocatalytic activity under fluorescent and visible light.

It can be concluded that co-doping of titania coatings with metallic and non-metallic elements provides a very promising route for the deposition of photocatalytic titania coatings with significant activity both under UV and fluorescent light sources. However, a synergistic effect of co-doping can be achieved when the concentration of both metal and non-metal are within some optimum range, therefore an optimisation study is required to maximise the photocatalytic properties of the coatings.

\section{Conclusions}

Co-doping of titanium dioxide with both a metal and a non-metal was investigated as a way of depositing coatings with high photocatalytic activity. Co-doped coatings were analysed and compared to coatings doped with either $\mathrm{N}$ or Mo alone, as well as to undoped titania. 
It was found that co-doping improves the solubility of the doping elements in the titania lattice, as well as significantly improving photocatalytic activity. Co-doped coatings exhibited higher band gap shifts towards the visible range, which was reflected in the existence of a low level of visible light activity and high photocatalytic activity under fluorescent light. Doping with metals and non-metallic elements simultaneously results in the creation of more impurity bands within the titania band gap and thus improves visible light absorption. Additionally, improved electron-hole separation for the co-doped coatings greatly improved the photocatalytic properties under UV light, compared to undoped or mono-doped titania.

Overall, Mo-N co-doped coatings look very promising as photocatalysts. Further enhancement of photocatalytic properties may be achieved by optimising deposition conditions and the concentrations of the doping elements. 


\section{References}

[1] Fujishima A, Zhang X. Titanium dioxide photocatalysis: present situation and future approaches. Comptes Rendus Chimie. 2006;9:750-60.

[2] Asahi R, Morikawa T, Ohwaki T, Aoki K, Taga Y. Visible-Light Photocatalysis in Nitrogen-Doped Titanium Oxides. Science. 2001;293:269-71.

[3] Tavares CJ, Marques SM, Viseu T, Teixeira V, Carneiro JO, Alves E, et al. Enhancement in the photocatalytic nature of nitrogen-doped PVD-grown titanium dioxide thin films. Journal of Applied Physics. 2009;106:113535--8.

[4] Chiu S-M, Chen Z-S, Yang K-Y, Hsu Y-L, Gan D. Photocatalytic activity of doped $\mathrm{TiO}_{2}$ coatings prepared by sputtering deposition. Journal of Materials Processing Technology. 2007;192-193:60-7.

[5] Wong M-S, Pang Chou H, Yang T-S. Reactively sputtered N-doped titanium oxide films as visible-light photocatalyst. Thin Solid Films. 2006;494:244-9.

[6] Pelaez M, Nolan NT, Pillai SC, Seery MK, Falaras P, Kontos AG, et al. A review on the visible light active titanium dioxide photocatalysts for environmental applications. Applied Catalysis B: Environmental. 2012;125:331-49.

[7] Liu H, Lu Z, Yue 1, Liu J, Gan Z, Shu C, et al. $(\mathrm{Mo}+\mathrm{N})$ codoped $\mathrm{TiO}_{2}$ for enhanced visible-light photoactivity. Applied Surface Science. 2011;257:9355-61.

[8] Choi W, Termin A, Hoffmann MR. The Role of Metal Ion Dopants in Quantum-Sized $\mathrm{TiO}_{2}$ : Correlation between Photoreactivity and Charge Carrier Recombination Dynamics. The Journal of Physical Chemistry. 1994;98:13669-79.

[9] Li XZ, Li FB, Yang CL, Ge WK. Photocatalytic activity of $\mathrm{WO}_{\mathrm{x}}-\mathrm{TiO}_{2}$ under visible light irradiation. Journal of Photochemistry and Photobiology A: Chemistry. 2001;141:209-17.

[10] Peng Y-H, Huang G-F, Huang W-Q. Visible-light absorption and photocatalytic activity of Cr-doped $\mathrm{TiO}_{2}$ nanocrystal films. Advanced Powder Technology. 2012;23:8-12.

[11] Akbarzadeh R, Umbarkar SB, Sonawane RS, Takle S, Dongare MK. Vanadia-titania thin films for photocatalytic degradation of formaldehyde in sunlight. Applied Catalysis A: General. 2010;374:103-9.

[12] Stengl V, Bakardjieva S, Murafa N. Preparation and photocatalytic activity of rare earth doped $\mathrm{TiO}_{2}$ nanoparticles. Materials Chemistry and Physics. 2009;114:217-26.

[13] Nolan NT, Synnott DW, Seery MK, Hinder SJ, Van Wassenhoven A, Pillai SC. Effect of $\mathrm{N}$-doping on the photocatalytic activity of sol-gel $\mathrm{TiO}_{2}$. Journal of Hazardous Materials. 2012;211-212:88-94.

[14] Cheng X, Yu X, Xing Z. Characterization and mechanism analysis of Mo-N-co-doped $\mathrm{TiO}_{2}$ nano-photocatalyst and its enhanced visible activity. Journal of Colloid and Interface Science. 2012;372:1-5. 
[15] Onifade AA, Kelly PJ. The influence of deposition parameters on the structure and properties of magnetron-sputtered titania coatings. Thin Solid Films. 2006;494:8-12.

[16] Rauf MA, Meetani MA, Hisaindee S. An overview on the photocatalytic degradation of azo dyes in the presence of $\mathrm{TiO}_{2}$ doped with selective transition metals. Desalination. 2011;276:13-27.

[17] Lorret O, Francová D, Waldner G, Stelzer N. W-doped titania nanoparticles for UV and visible-light photocatalytic reactions. Applied Catalysis B: Environmental. 2009;91:39-46.

[18] Ratova M, Kelly PJ, West GT, Iordanova I. Enhanced properties of magnetron sputtered photocatalytic coatings via transition metal doping. Surface and Coatings Technology. 2013;228, Supplement 1:S544-S9.

[19] Fuerte A, Hernandez-Alonso MD, Maira AJ, Martinez-Arias A, Fernandez-Garcia M, Conesa JC, et al. Visible light-activated nanosized doped- $\mathrm{TiO}_{2}$ photocatalysts. Chemical Communications. 2001:2718-9.

[20] Long M, Wang J, Zhuang $\mathrm{H}$, Zhang $\mathrm{Y}$, Wu H, Zhang J. Performance and mechanism of standard nano- $\mathrm{TiO}_{2}$ (P-25) in photocatalytic disinfection of foodborne microorganisms Salmonella typhimurium and Listeria monocytogenes. Food Control. 2014;39:68-74.

[21] Tauc J, Grigorovici R, Vancu A. Optical Properties and Electronic Structure of Amorphous Germanium. physica status solidi (b). 1966;15:627-37.

[22] Qin H-L, Gu G-B, Liu S. Preparation of nitrogen-doped titania with visible-light activity and its application. Comptes Rendus Chimie. 2008;11:95-100.

[23] Kralchevska R, Milanova M, Hristov D, Pintar A, Todorovsky D. Synthesis, characterization and photocatalytic activity of neodymium, nitrogen and neodymiumnitrogen doped $\mathrm{TiO}_{2}$. Materials Research Bulletin. 2012;47:2165-77. 
List of Tables

Table . Compositional properties and thickness of titania coatings doped with nitrogen ('N' series) and co-doped with molybdenum / nitrogen ('MoN'series)

Table 2: Band gap values and MB degradation rate constants for N-doped and Mo-N codoped titania coatings

\section{List of Figures}

Figure 1: Schematic representation of the Teer Coatings Ltd. UDP450 sputtering rig with three planar magnetrons

Figure 2: Results of Raman spectroscopy for N-doped titania coatings deposited on glass substrates and annealed at $873 \mathrm{~K}$ (A denotes the anatase phase peak positions)

Figure 3: Results of Raman spectroscopy of Mo-N co-doped titania coatings deposited on glass substrate and annealed at $873 \mathrm{~K}$ (A denotes the anatase phase peak positions)

Figure 4: XRD patterns of $\mathrm{N}$-doped titania coatings deposited on glass substrate and annealed at $873 \mathrm{~K}$ (A denotes anatase phase).

Figure 5: XRD patterns of Mo-N co-doped titania coatings deposited on glass substrate and annealed at $873 \mathrm{~K}$ (A denotes anatase phase, $\mathrm{B}$ - brookite and $\mathrm{R}$ - rutile).

Figure 6.Curve fitting on Mo3d XPS spectra of coatings MoN3 (left) and MoN7 (right)

Figure 7.Curve fitting on Mo3p and N1s XPS spectra of coatings MoN3 (left) and MoN7 (right)

Figure 8.Curve fitting on N1s XPS spectra of coatings N3 (left) and N7 (right)

Figure 9: Example of the optical band gap calculation for N-doped and Mo-N co-doped titania coatings annealed at $873 \mathrm{~K}$

Figure 10: Example of MB $665 \mathrm{~nm}$ absorbance peak decay for different coatings

Figure 10: Schematic representation of electron-hole transfer in co-doped coatings [14] 
Table 1

\begin{tabular}{lllll}
\hline $\begin{array}{c}\text { Dopan } \\
\mathbf{t}\end{array}$ & \multicolumn{1}{c}{$\begin{array}{c}\text { Sample } \\
\text { ID }\end{array}$} & $\begin{array}{c}\text { Flow of nitrogen, } \\
\text { sccm }\end{array}$ & $\begin{array}{c}\text { Content of nitrogen, } \\
\text { at. } \%\end{array}$ & $\begin{array}{c}\text { Coating thickness, } \\
\text { nm }\end{array}$ \\
\hline Mo & $\mathrm{TiO}_{2}+\mathrm{Mo}$ & - & - & 685 \\
\hline $\mathbf{N}$ & $\mathrm{N} 1$ & 1 & $<1 \%$ & 654 \\
& $\mathrm{~N} 3$ & 3 & $<1 \%$ & 657 \\
& $\mathrm{~N} 5$ & 5 & $<1 \%$ & 654 \\
& $\mathrm{~N} 7$ & 7 & 1.09 & 658 \\
& $\mathrm{~N} 10$ & 10 & 3.67 & 661 \\
\hline Mo+N & MoN1 & 1 & 1.22 & 760 \\
& MoN3 & 3 & 3.08 & 764 \\
& MoN5 & 5 & 4.95 & 758 \\
& MoN7 & 7 & 7.13 & 761 \\
& MoN10 & 10 & 9.12 & 766 \\
\hline
\end{tabular}


Table 2

\begin{tabular}{|c|c|c|c|c|c|}
\hline Sample ID & Band gap, eV & $\begin{array}{c}\text { Band gap } \\
\text { shift } \\
\text { (compared } \\
\text { to } \mathrm{TiO}_{2} \text { ) }\end{array}$ & $\begin{array}{c}k_{a} \times 10^{-5}, s^{-1} \\
\text { UV light }\end{array}$ & $\begin{array}{l}k_{a} \times 10^{-5}, s^{-1} \\
\text { Fluor. light }\end{array}$ & $\begin{array}{l}k_{a} \times 10^{-5}, s^{-1} \\
\text { Vis. light }\end{array}$ \\
\hline $\mathrm{TiO}_{2}$ & 3.15 & - & 1.7 & 0.6 & 0 \\
\hline $\mathrm{TiO}_{2}+\mathrm{Mo}$ & 3.00 & -0.15 & 2.8 & 1.8 & 0.6 \\
\hline N1 & 3.22 & +0.07 & 3.6 & 0.9 & 0 \\
\hline $\mathbf{N 3}$ & 3.22 & +0.07 & 2.9 & 1.6 & 0 \\
\hline N5 & 3.20 & +0.05 & 1.7 & 1.1 & 0 \\
\hline N7 & 3.14 & -0.01 & 1.7 & 1.0 & 0 \\
\hline N10 & 3.08 & -0.07 & 1.4 & 0.9 & 0 \\
\hline MoN1 & 3.09 & -0.06 & 1.0 & 0.6 & 0 \\
\hline MoN3 & 3.09 & -0.06 & 4.9 & 1.7 & 0.4 \\
\hline MoN5 & 3.05 & -0.10 & 6.9 & 2.1 & 0.7 \\
\hline MoN7 & 3.04 & -0.11 & 7.5 & 5.6 & 1.2 \\
\hline MoN10 & 3.07 & -0.08 & 5.6 & 3.7 & 1.0 \\
\hline
\end{tabular}




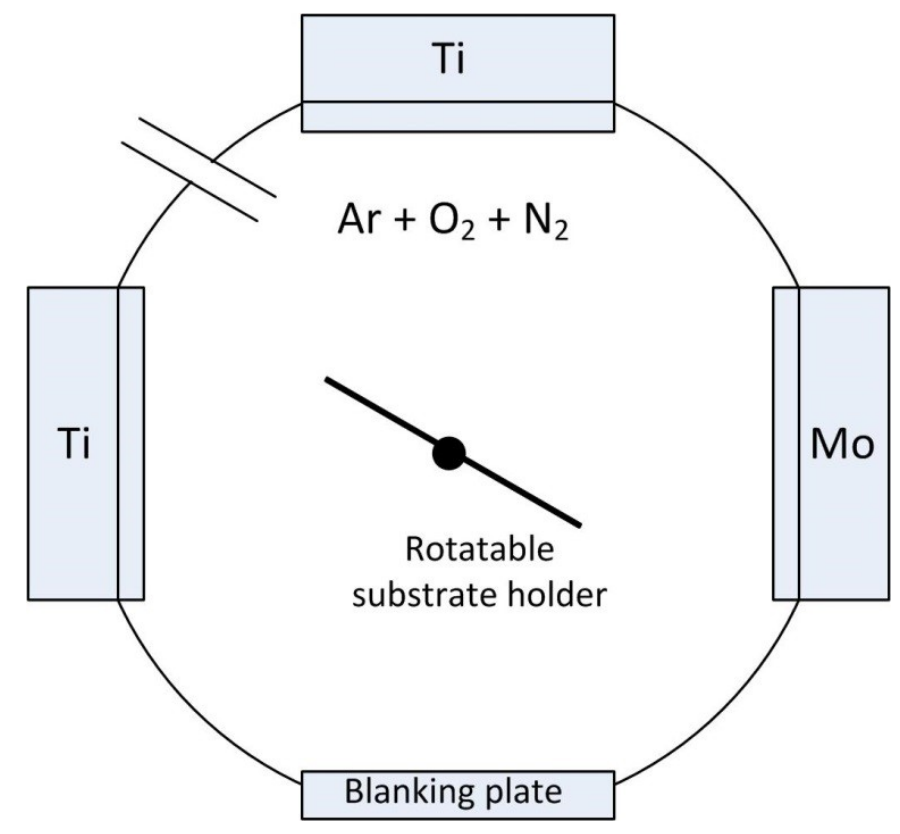

Fig. 1 


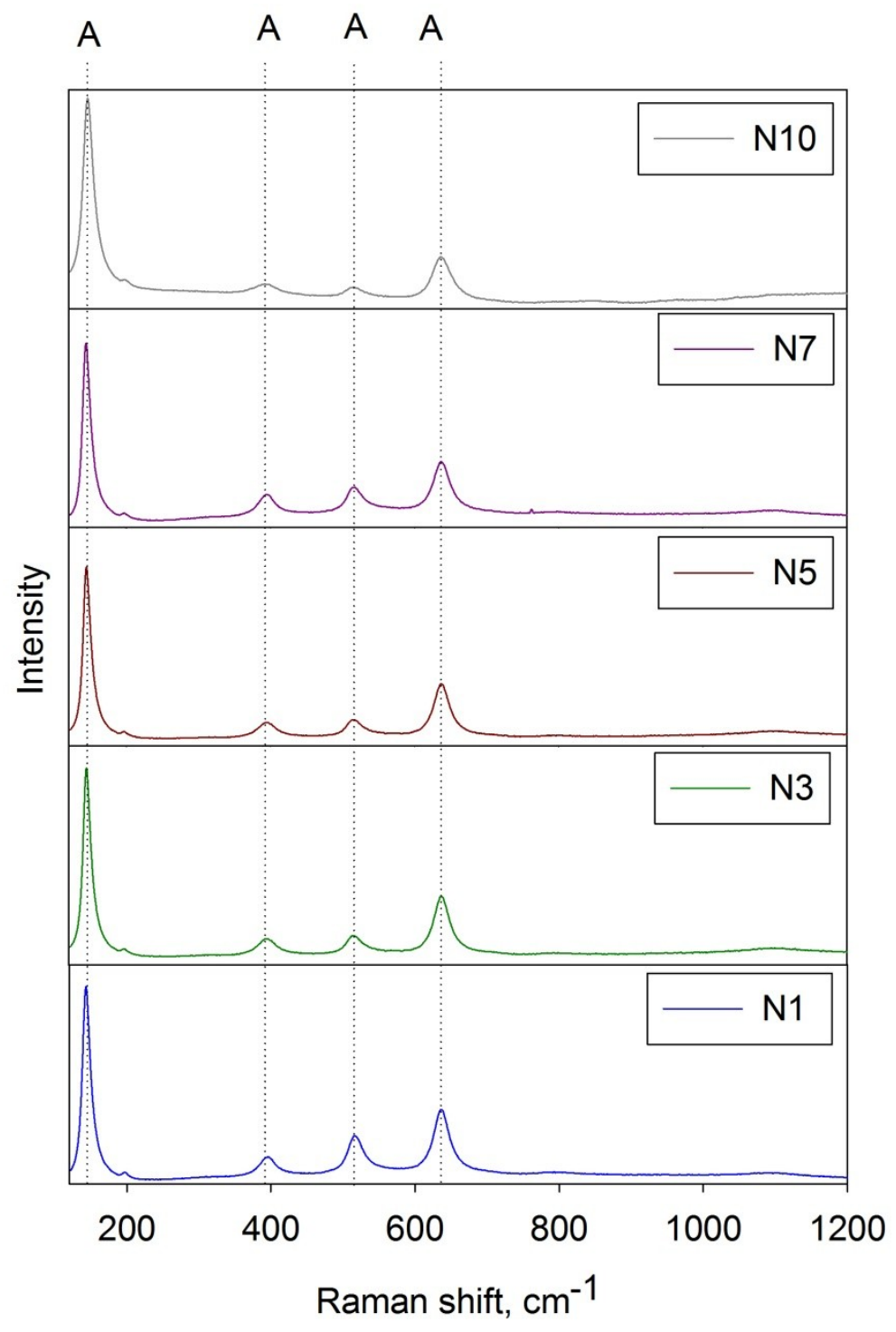

Fig. 2 


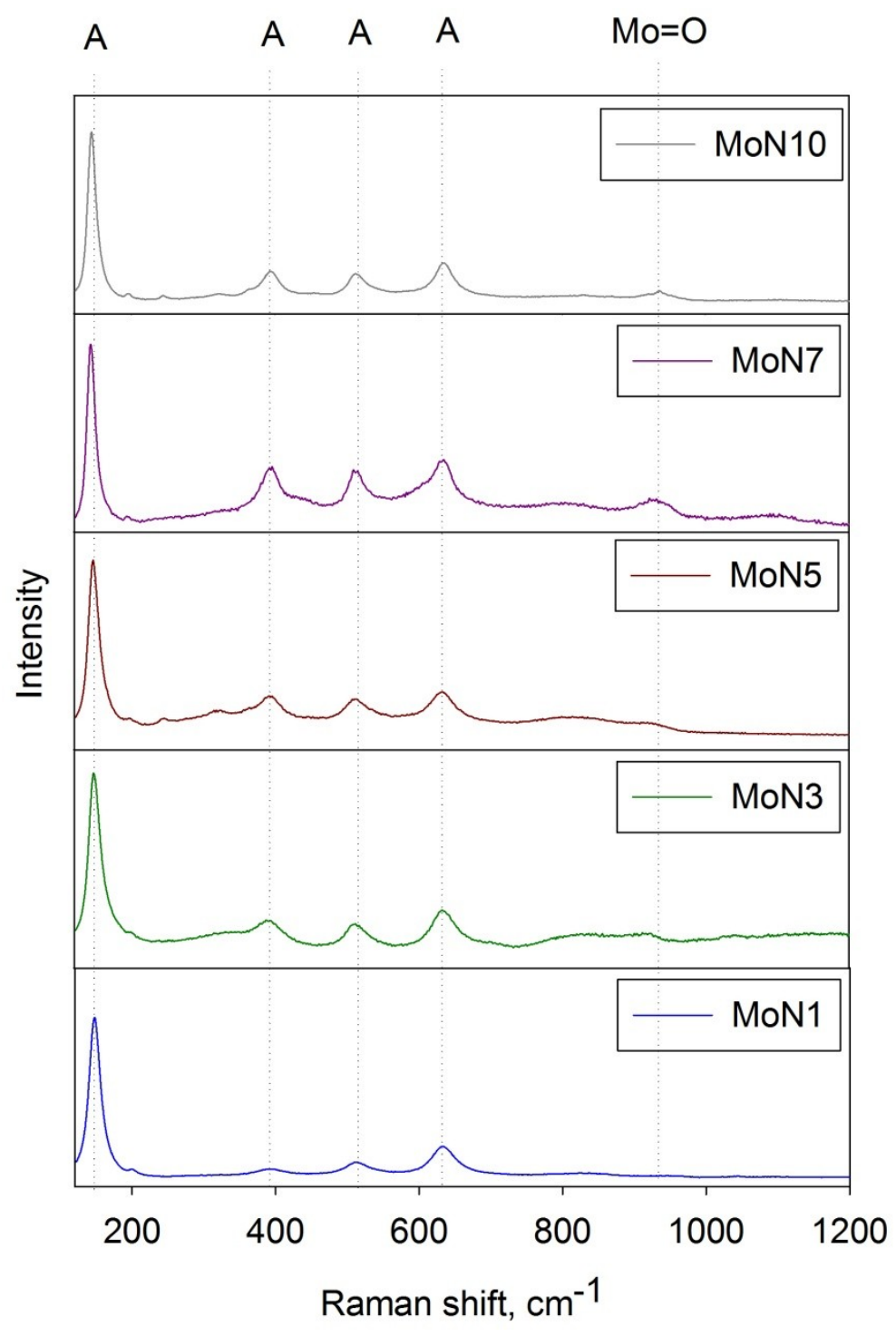

Fig. 3 


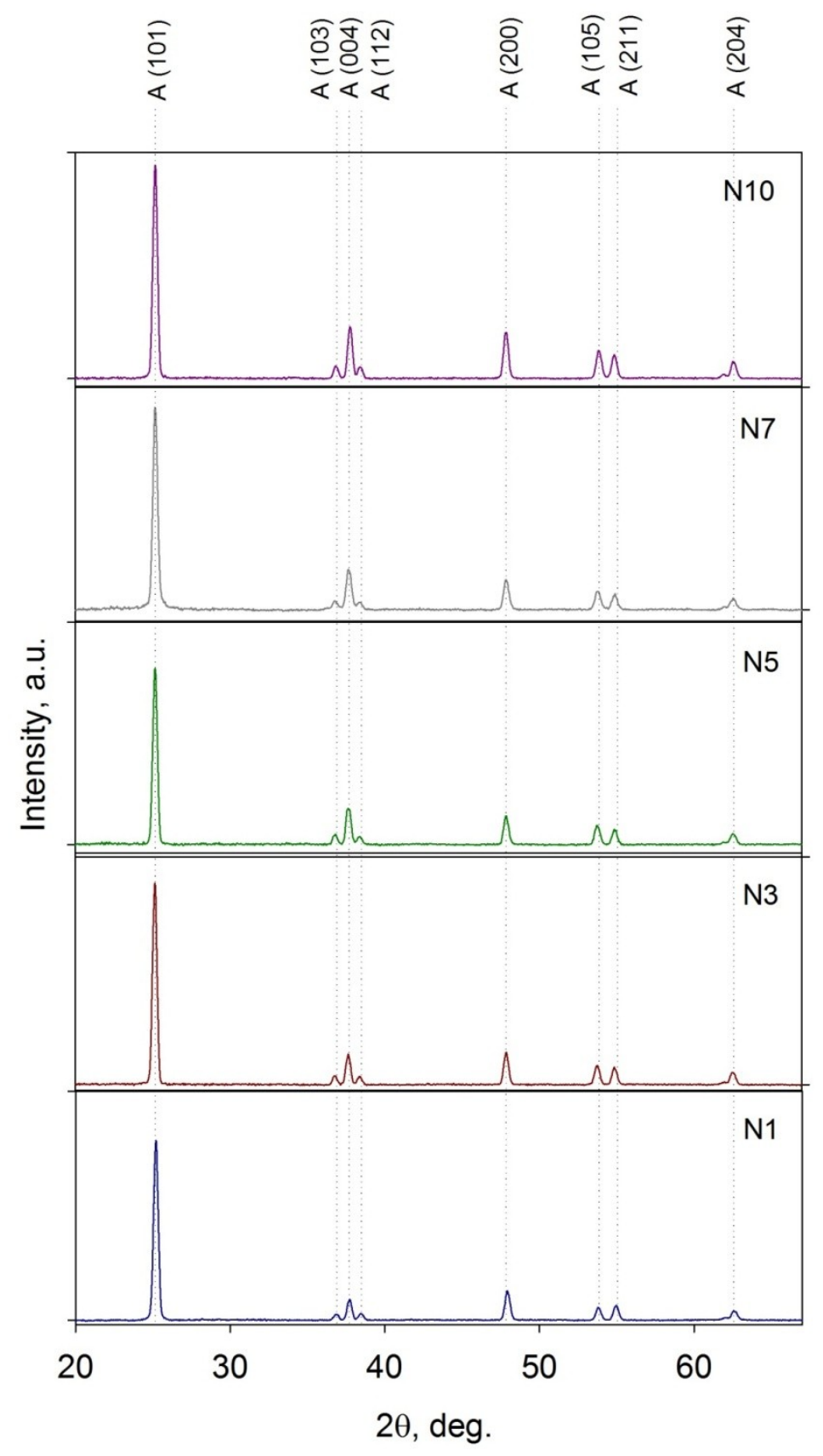

Fig. 4 


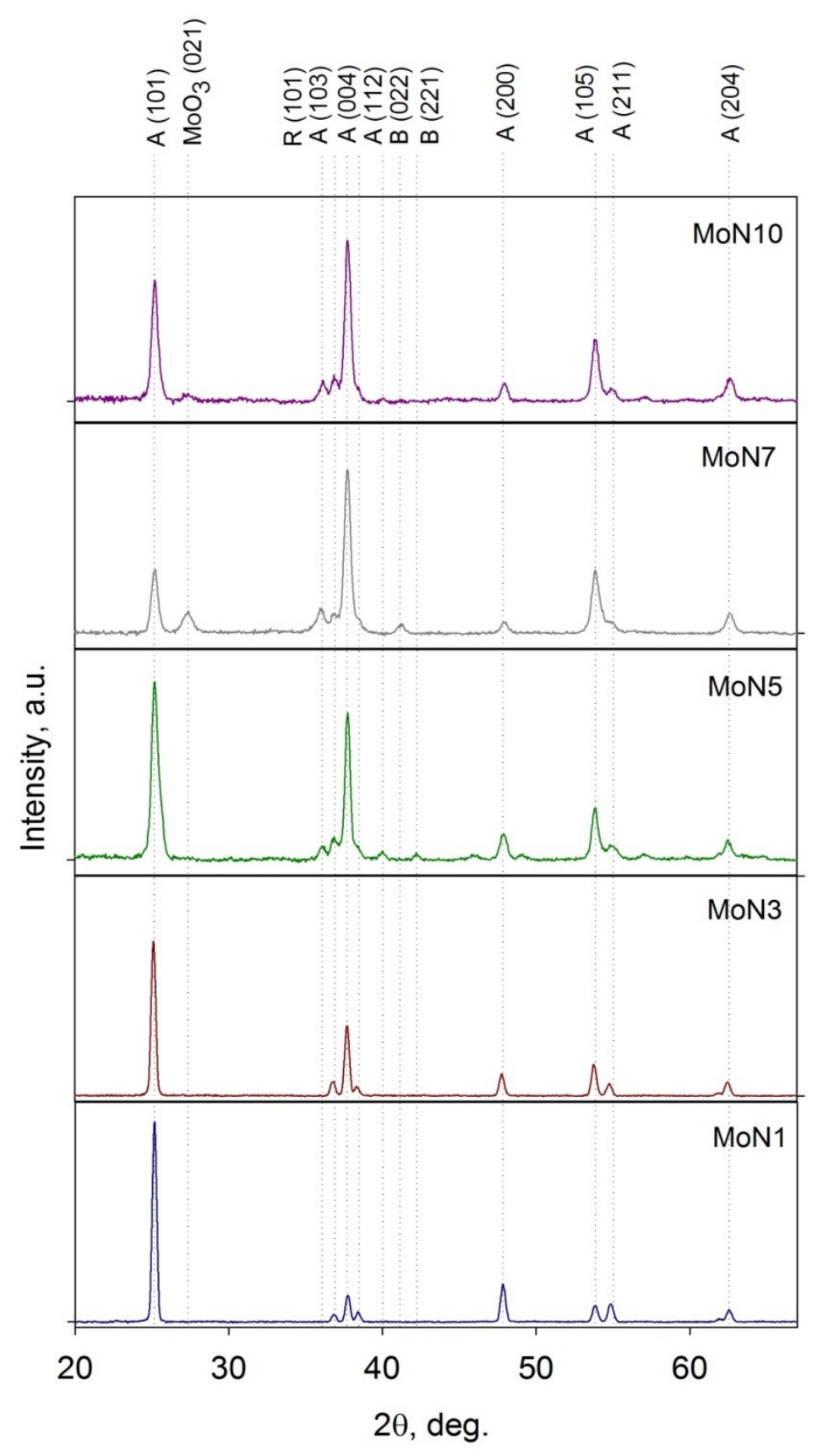

Fig. 5 

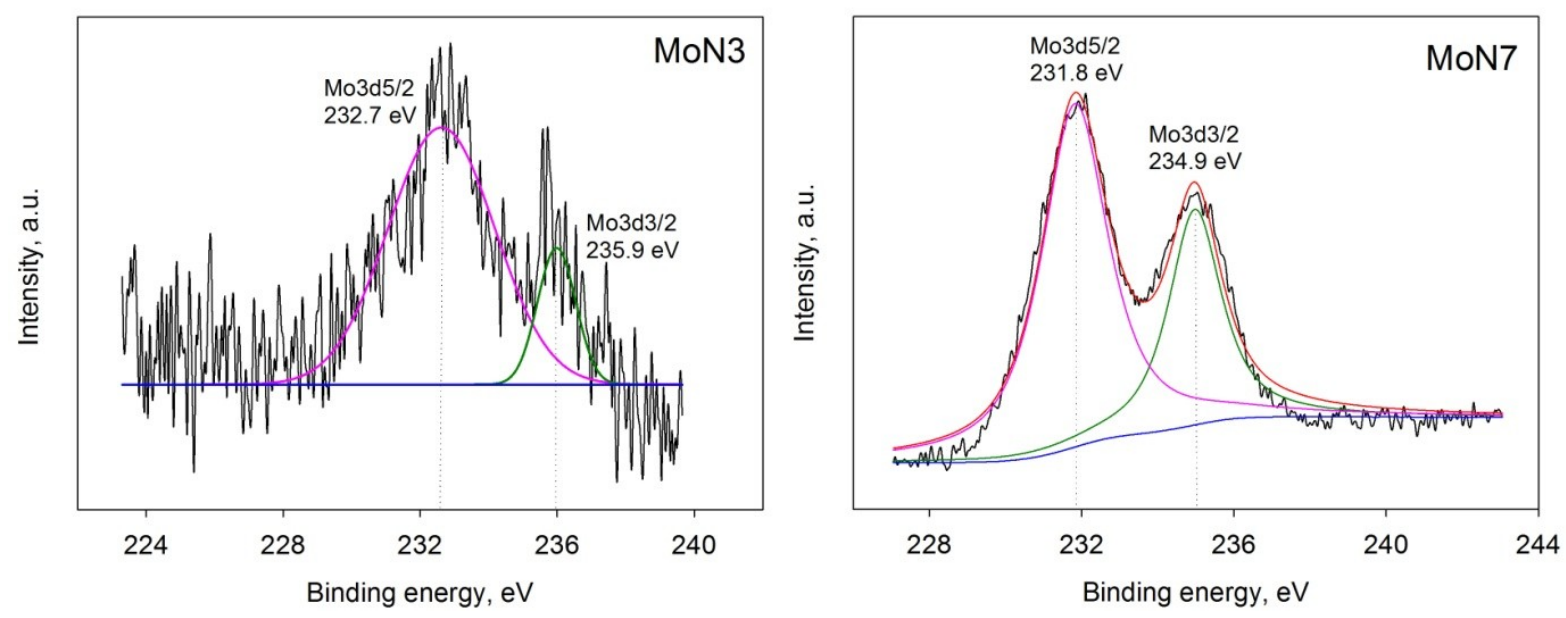

Fig. 6
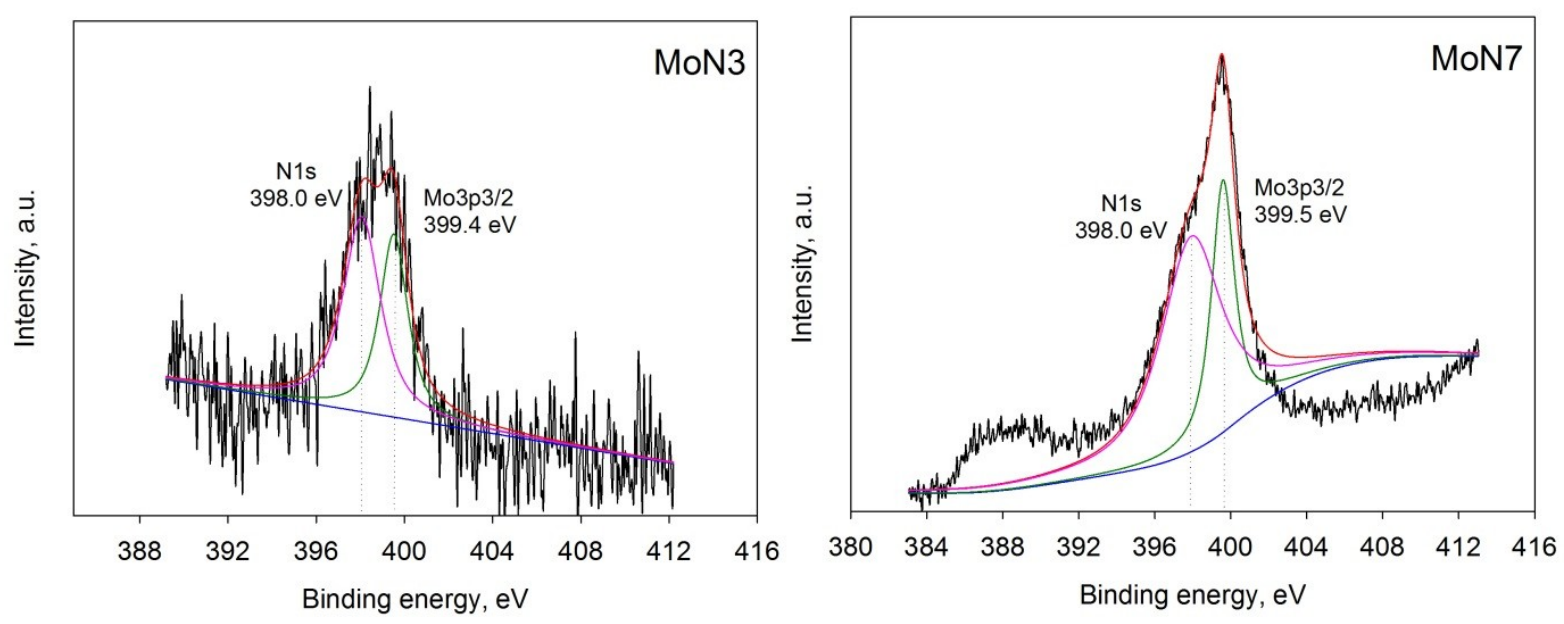

Fig. 7 


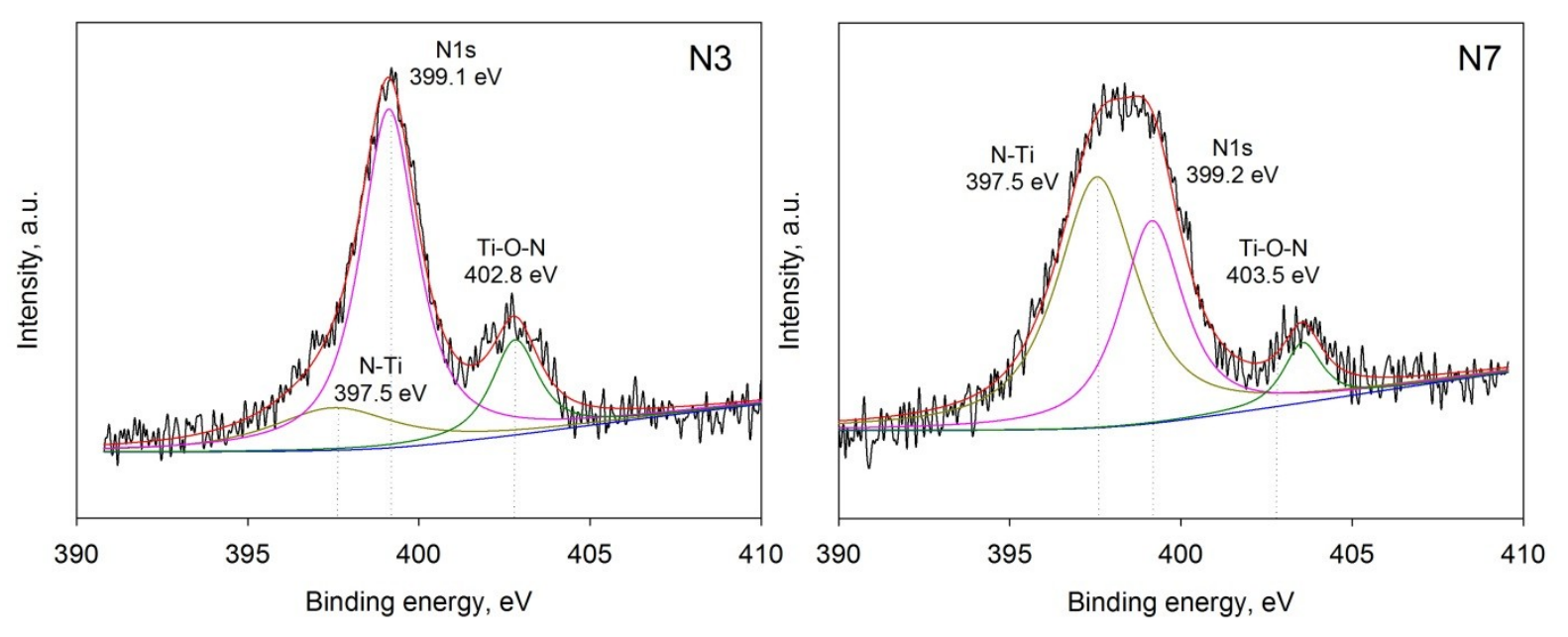

Fig. 8

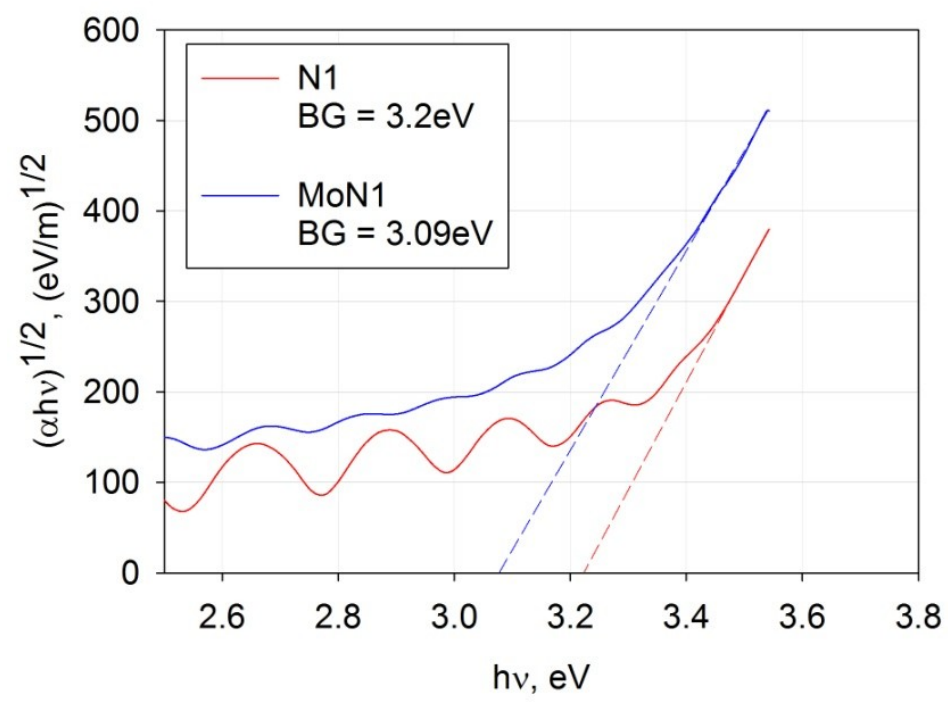

Fig. 9 


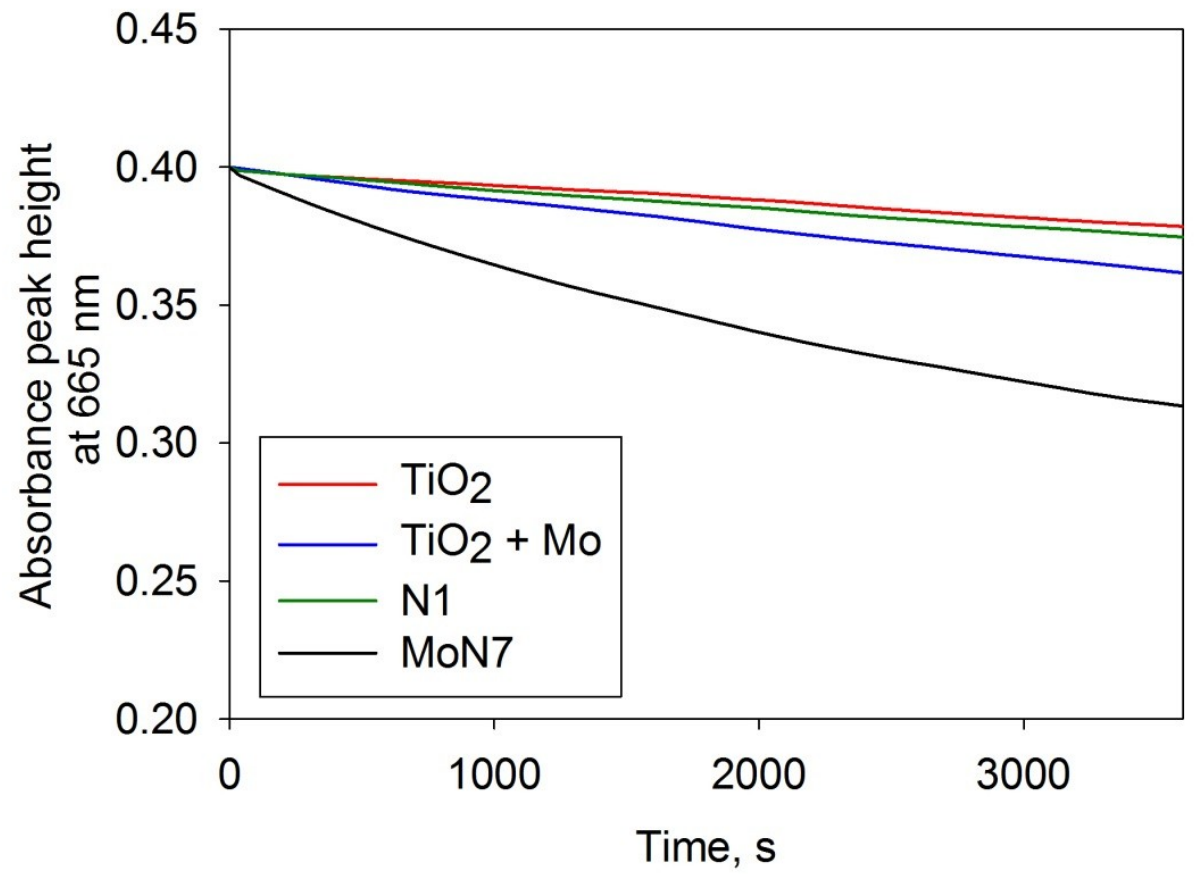

Fig. 10

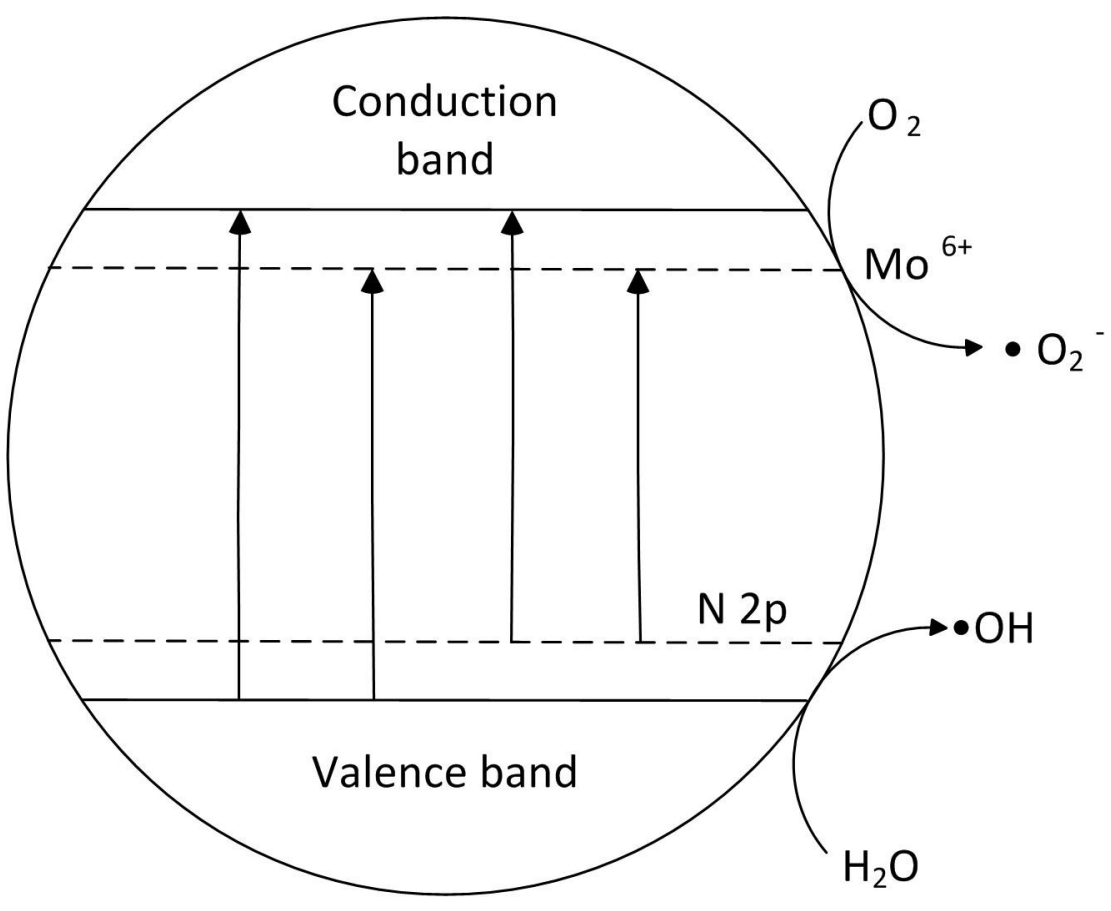

Fig. 11 